\title{
A Fire Danger Index for the early detection of areas vulnerable to wildfires in the Eastern Mediterranean region
}

\author{
Panteleimon Xofis ${ }^{1} \mathbb{D} \cdot$ Georgios Tsiourlis $^{2} \cdot$ Pavlos Konstantinidis $^{2}$
}

Received: 13 January 2020 / Accepted: 3 June 2020 / Published online: 26 June 2020

(c) The Author(s) 2020

\begin{abstract}
Wildfires continue to be a major factor of disturbance to Mediterranean ecosystems, and are often associated with significant losses of properties and human lives. Fast fire detection and suppression within the first few minutes after ignition are crucial to successfully managing wildfires and preventing their potentially catastrophic consequences. In this study, remote-sensing methods and data were integrated wih fire behavior simulation and field data to develop a Fire Danger Index (FDI) that can be used to detect the areas most vulnerable to wildfires. This FDI will be integrated into an automatic fire detection system that utilizes optical and thermal land cameras and an unmanned aerial vehicle. The FDI was calculated for a nature reserve in Southern Greece based on fire behavior, pyric history, and anthropogenic influence. Fire behavior was estimated using the FlamMap fire simulation model, while the fuel types to include in the model were determined using state-of-the-art remote-sensing methods and field data. The pyric history was represented by point data on fire occurrences over a period of 40 years. The anthropogenic influence was estimated based on an inverse relationship of this influence with the Euclidean distance from roads and settlements. The calculated FDI demonstrated that a large part of the reserve, including its most ecologically important ecosystems, is highly vulnerable to wildfires. Integrating the FDI into the automatic fire detection system is expected to significantly improve its detection accuracy.
\end{abstract}

Keywords Forest fires $\cdot$ Fire Danger Index $\cdot$ Remote sensing $\cdot$ Fire detection

\section{Introduction}

Fire is an important ecological factor that has affected the structure and distribution of numerous plant communities across the globe. Prior to human activities, the main ignition sources were lightning, volcanic eruptions, and earthquakes. Fire has since become a very important human tool that has been widely used and misused to improve living conditions (Naveh 1990). Both the frequency and intensity of fires have increased dramatically under the influence of anthropogenic

Communicated by Dimitra Vagiona, Lead Guest Editor.

Panteleimon Xofis

pxofis@for.ihu.gr

1 Department of Forestry and Natural Environment, International Hellenic University, 1st km Drama-Mikrohori, 66100 Drama, Greece

2 ELGO-DEMETER, Hellenic Agricultural Organization "Demeter" (formerly the National Agricultural Research Foundation, NAGREF), Forest Research Institute, 57006, Vassilika, Thessaloniki, Greece activities, resulting in major impacts on natural ecosystems and Mediterranean flora. This change in fire characteristics has shifted the equilibrium between fire and ecosystem function, transforming fire from a natural ecological factor that initiates succession into a human-induced land degradation factor.

Wildfires, especially large ones, result from the combined action of two driving forces: weather patterns and fuel availability and continuity. Over the last few years, significant efforts have been made to study the historic and current trends in the wildfire regime and to identify the influence of these driving forces on past and current wildfire regimes (Dimitrakopoulos et al. 2011; Pausas and Fernandez-Munoz 2012; Koutsias et al. 2013; Turco et al. 2016). Despite differences between the approaches employed in terms of the sources of data used, the period studied, and the uncertainty when using historical data dating back to the beginning of the twentieth century, all of these studies reached the same conclusion. They noted a change in the fire regime of Mediterranean Europe after the 1970s, with a significant increase in both the total number of fires (NF) and the area burned (AB). A correlation between 
wildfire activity and weather conditions was observed, with drought conditions favoring wildfires, and this correlation became much stronger after the 1970s. This is a clear indication that wildfires have changed from being fuel driven before the 1970s to weather driven after that period.

Despite an increase in the resources allocated to fire suppression, wildfires continue to constitute a major disturbance factor that threatens ecosystem integrity, infrastructure, and properties. Wildfire management needs to be rethought, with increased attention paid to fire prevention and rapid fire detection. The identification of vulnerable areas and ecosystems that can be managed in a way that will prevent large and catastrophic fires is certainly a step in the right direction (Ager et al. 2014). Today there are a wide range of methods and applications involving geographic information systems, remote sensing data and methods, and simulated fire behavior that are useful tools for planning and managing wildfires. Molina et al. (2017) integrated several components of fire risk (fine fuel moisture content, physiographic parameters, weather data, and vegetation flammability) to develop an ignition index for application at the wildland-urban interface (WUI). Mitsopoulos et al. (2015) assessed the wildfire risk using fuel data, fire simulations (via FlamMap), and different scenarios for burning conditions, providing a spatially explicit estimation of wildfire potential in the WUI of Attica in Greece. The fire weather index (FWI) has also been widely used to estimate the fire risk resulting from weather conditions, land use, and seasonality; the resulting risk data can be used to ensure that fire fighting forces are prepared and alert during high-risk periods (Ager et al. 2014). Remote-sensing methods and data are also extremely valuable in the effort to manage and reduce the destructive power of wild fires. When used in combination with advanced analytical approaches, the high spatial, thematic, and temporal resolution of contemporary remotesensing data permits spatially and thematically accurate vegetation and fuel mapping, which can be successfully integrated into fire risk analysis (Keramitsoglou et al. 2008; Sanchez et al. 2018).

In the current study, remote-sensing methods and data were integrated with anthropogenic factors, pyric history, vegetation flammability properties, and fire simulation methods to develop a Fire Danger Index (FDI). The developed FDI will allow the identification of vulnerable areas that could be properly managed to reduce the risk of a potential megafire. Furthermore, this spatially explicit FDI can be integrated into an automatic fire detection system that utilizes optical and thermal land cameras and UAVs.

\section{Materials and methods}

\section{Study area}

The study was conducted in the Kotychi and Strofylia Wetlands National Park in southeast Greece $\left(38^{\circ} 6^{\prime} 4^{\prime \prime} \mathrm{N}\right.$, $21^{\circ} 21^{\prime} 32^{\prime \prime} \mathrm{E}$; Fig. 1). This has been a designated national park since 2002 and is currently governed by the Management Body of Kotychi and Strofylia Wetlands. Due to its high biodiversity and unusually high aesthetic value, a number of protection designations have been assigned to the area. Part of it was recognized as a Wetland of International Importance in 1975, when it was included in the ten wetlands of Greece that were protected under the RAMSAR Convention. Later, parts of the area were recognized as Special Protection Areas (SPAs) for birds in accordance with EC Directive 2009/147/EE, and as Sites of Community Importance (SCIs) in accordance with EC Directive 92/43/EEC, which led to the establishment of the European NATURA 2000 network of protected areas. The study area has a typical Mediterranean climate, characterized by warm and wet winters and hot and dry summers. Based on the weather data collected by the weather station at Araxos, which is the closest station to the study area, the mean annual temperature was $17.8^{\circ} \mathrm{C}$ and the mean annual precipitation was $688 \mathrm{~mm}$ over the period 1955-1997. The hottest month is August, with a mean temperature of $26.8^{\circ} \mathrm{C}$, and the coldest is January, with a mean temperature of $10.2{ }^{\circ} \mathrm{C}$. The mean annual maximum temperature ranges from 21.9 to $31.0^{\circ} \mathrm{C}$, while the mean annual minimum temperature ranges from 5.1 to $12.2^{\circ} \mathrm{C}$. The wettest month is November, with a mean total precipitation of $132 \mathrm{~mm}$, while the driest is July, with a mean total precipitation of $3.6 \mathrm{~mm}$. The dominant species in the forested parts of the study area are Pinus pinea and $P$. halepensis, while there are several different vegetation formations, including Quercus aegilops stands, shrublands dominated by Juniperus phoenicea, grasslands with scattered short shrubs, and wet meadows.

\section{Data and methods}

The FDI developed in the current study is mainly based on two important components of the fire regime: anthropogenic activity and fuel availability and burnability. It also considers the pyric history of the area, which can indicate 
Fig. 1 Location of the study area

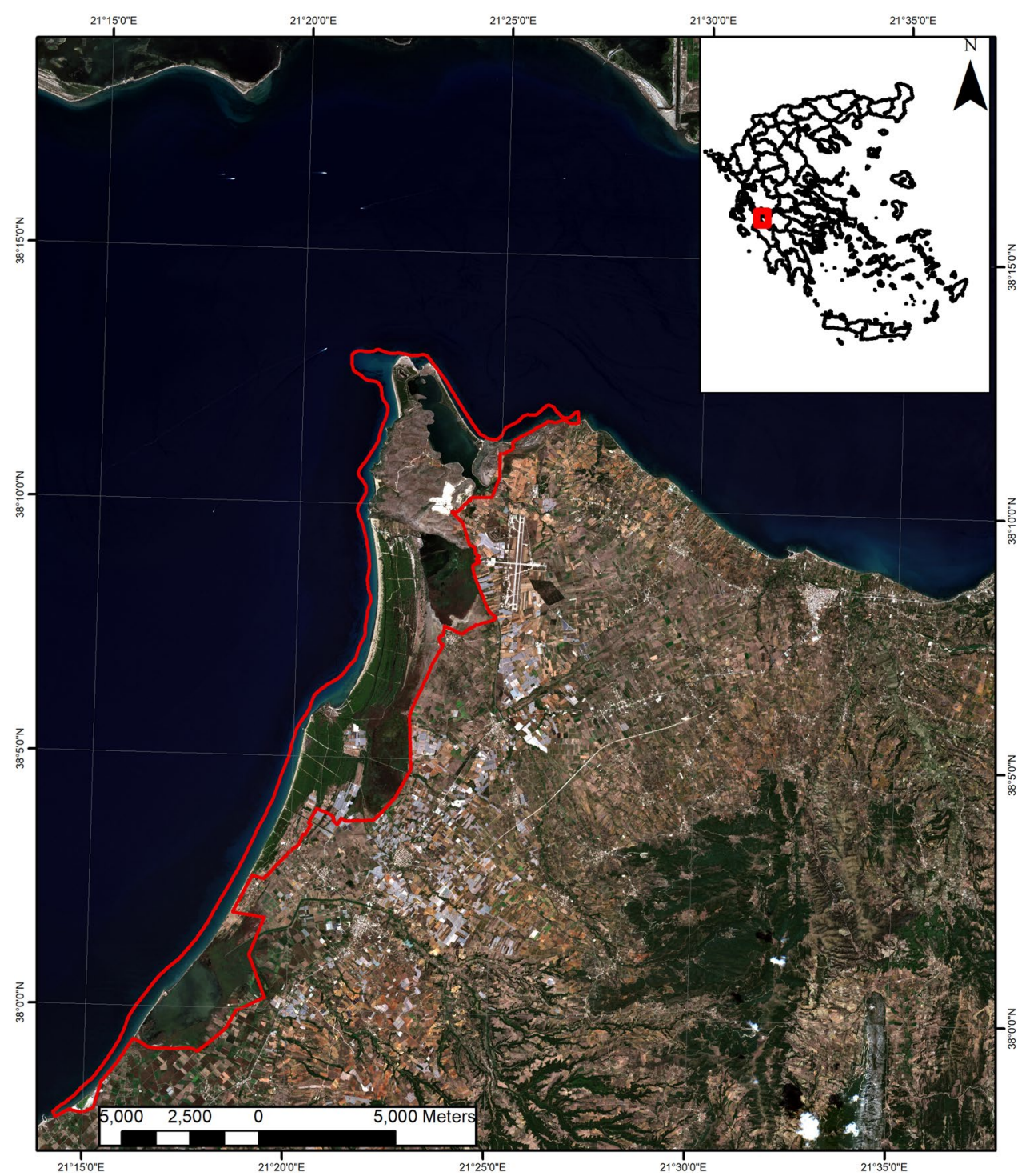

the potential vulnerability of the area. Fuel availability was determined from remote-sensing data and methods along with in situ data on the structural and compositional characteristics of the vegetation in the area. Anthropogenic activity was integrated into the FDI using the distance to the nearest road or settlement. The pyric history was incorporated after collecting all fire records from the last 40 years for the area from the local forest service and transforming these records into a raster GIS.

To identify and map the vegetation types in the area, very high spatial resolution (VHR) aerial photographs were integrated with high-resolution (HR) satellite images in an object-oriented analysis (OBIA) environment using the software eCognition (Trimble Inc. 2014). Integration of VHR and HR data allowed us to use the VHR data to accurately delineate the various land cover types and to use the HR data (which had better temporal and spectral resolution) for thematically accurate land cover classification (Xofis and
Poirazidis 2018). The VHR aerial photographs, which were provided by the Greek National Cadastral Organization, had a spatial resolution of $0.25 \mathrm{~m}$ and a thematic resolution that covered the visual and the near-infrared parts of the electromagnetic spectrum. A time series dataset of four Sentinel 2 images acquired in August 2018, December 2018, March 2019, and May 2019, respectively, was compiled. Sentinel 2 is a constellation of two polar-orbiting satellites launched by ESA as part of the Copernicus program (formerly known as GMES; Drusch et al. 2012). These satellites deliver multispectral data at a spatial resolution of up to $10 \mathrm{~m}$ in the visual and near-infrared bands and high thematic resolution at spatial resolutions of 20 and $60 \mathrm{~m}$, with a revisiting frequency of 5 days. All images were processed at level 2A, and the ten bands at spatial resolutions of 10 and $20 \mathrm{~m}$ were used.

Ancillary vector data were also employed to delineate agricultural and urban areas. The classification process was 
assisted by ground truth data collected in situ at 50 plots in May 2018, where the land cover type was recorded as well as a number of structural characteristics that were also used to estimate fuel characteristics. Training data were also collected through visual inspection of the VHR aerial photographs. Various classifiers were tested for their effectiveness at identifying the selected classes. The performance of each classifier was assessed as its efficiency at reproducing the training set. The random forests algorithm was found to be the best-performing classifier for this study area and the data used (the other classifiers tested were the classification trees, support vector machines, and k-nearest neighbor algorithms). Various postclassification refinements were employed in order to avoid a "salt and pepper" result. Isolated objects that were surrounded by one particular class and were smaller than the minimum mapping unit ( $0.25 \mathrm{ha}$ ) were assigned to the enclosing class. Furthermore, each isolated object that was smaller than the minimum mapping unit and neighbored more than one class was assigned to the class with which it had the longest common border. Eleven classes representing different land cover types were identified in total. The accuracy of the final product was assessed using an error matrix based on 142 randomly distributed independent observations for which the true land cover type was verified in situ.

The first step in OBIA is the generation of objects based on the spectral similarity of neighboring pixels. The degree of homogeneity of each object is determined by the user, who sets an appropriate scale parameter (Bock et al. 2005). Normally, the final stage of the classification process involves merging neighboring objects belonging to the same class. However, this was not done in the present work; the objects used during the classification process were also used in the next stage, where a fuel model (FM) was assigned to each object based on the land cover type and the vegetation structural characteristics of the closest sample plot, forming a fuel map. This allowed the variation in structural characteristics observed within the same vegetation type to be represented in the fuel map.

As mentioned above, a survey was conducted in the 50 plots in the part of the study area covered by woody vegetation according to a stratified random sampling design. The stratification was made using a CORINE land cover map. All trees and shrubs in each plot were recorded, along with a number of measurements such as breast height diameter (BHD), tree height (used to calculate canopy height), live and dead crown base height, crown diameter, and canopy cover. For shrubs, the diameter at ground level was recorded instead of BHD. Litter depth was measured, and the existence and average estimated diameter of dead branches were recorded. The field data included some parameters that significantly influence fire behavior, such as dominant species, vegetation cover, crown density, crown base height, tree height, and crown perimeter. Those data were used in literature-derived allometric equations to obtain a rough estimation of the fuel load present in each plot (Tsiourlis 1992, 1994, 1998; Tsiourlis and Kasapidis 1999; Smiris et al. 2000; Tsiourlis et al. 2003; Ruiz-Peinado et al. 2011; Nunes et al. 2013). These estimations, along with pictures and notes taken for each plot, were used in the process of assigning each plot to one of the fuel models (FMs) described in the literature for similar areas (Anderson 1982; Dimitrakopoulos 2002; Scott and Burgan 2005; Palaiologou 2015; Kalabokidis et al. 2015). The land cover types of nonwoody

Table 1 Fuel models used in the study for the identified land cover types

\begin{tabular}{|c|c|c|c|}
\hline FM code & Description & Coresponding land cover type(s) & Source \\
\hline FM01 & $\begin{array}{l}\text { Pine forests with a shrub understorey covering more } \\
\text { than } 50 \% \text { of the area }\end{array}$ & Pure or mixed stands with $P$. pinea and $P$. halepensis & Palaiologou (2015) \\
\hline FM02 & $\begin{array}{l}\text { Pine forests with a shrub understorey covering less } \\
\text { than } 50 \% \text { of the area }\end{array}$ & Pure or mixed stands with $P$. pinea and $P$. halepensis & Palaiologou (2015) \\
\hline FM03 & Pine forests with an occasional shrub understorey & Pure or mixed stands with $P$. pinea and $P$. halepensis & Palaiologou (2015) \\
\hline GS1 & Low load, dry climate grass-shrub & Grasslands & Scott and Burgan (2005) \\
\hline GS3 & $\begin{array}{l}\text { Moderate load, humid climate grass-shrub } \\
\text { (dynamic) }\end{array}$ & Recently burned areas & Scott and Burgan (2005) \\
\hline GS4 & High load, humid climate grass-shrub (dynamic) & Wet meadows & Scott and Burgan (2005) \\
\hline $\mathrm{SH} 2$ & Moderate load, dry climate shrub & J. phoenicea shrublands (moderate density) & Scott and Burgan (2005) \\
\hline $\mathrm{SH} 7$ & Very high load, dry climate shrub & $\begin{array}{l}J \text {. phoenicea shrublands (high density), artificially } \\
\text { regenerated stands of } P \text {. halepensis and } P \text {. pinea } \\
\text { not exceeding } 8 \mathrm{~m} \text { in height }\end{array}$ & Scott and Burgan (2005) \\
\hline TU1 & Low load, dry climate timber-grass-shrub (dynamic) & Q. aegilops stands & Scott and Burgan (2005) \\
\hline NB3 & Agricultural areas & Agricultural areas & Scott and Burgan (2005) \\
\hline NB8 & Open water & Sea and inland water & Scott and Burgan (2005) \\
\hline NB9 & Bare ground & Bare ground & Scott and Burgan (2005) \\
\hline
\end{tabular}


vegetation and unvegetated sites, as identified in the OBIA, were also assigned one of the standard fuel models described by Scott and Burgan (2005) based on the descriptions provided and in situ visual inspections. All FMs used in the study along with the corresponding land cover types are shown in Table 1, while a full description of their properties is shown in the Table 3 in the Appendix.

In the next step, the FM of the nearest plot of the same land cover type was assigned to each of the polygons generated during the OBIA. Using the same approach, the structural characteristics canopy height $(\mathrm{CH})$, canopy cover $(\mathrm{CC})$, and canopy base height $(\mathrm{CBH})$ were assigned to each polygon. As a result, four raster data sets that were required for the fire simulation were generated.

The generated raster data, along with a digital elevation model (DEM), a digital aspect model (DAM), and a digital slope model (DSLM), were used in the fire simulation model FlamMap (Finney 2006) to estimate the potential fireline intensity and fire rate of spread. All raster data used in the fire simulation are shown in Fig. 2. The fireline intensity and fire rate of spread estimated in FlamMap were rescaled to a scale of 0 to 1 to produce the fire intensity (FI) index and the rate of spread (ROS) index for integration into the final FDI. A west wind with a velocity of 6 Beaufort was assumed for the simulation, and a dry fuel moisture scenario was adopted. The crown bulk density (CBD) was set at $0.3 \mathrm{~kg} / \mathrm{m}^{3}$ for all fuels.

The anthropogenic activity was integrated into the final FDI using the distance from roads and settlements. A raster dataset representing the Euclidean distance from all roads and settlements in the study area was created. When the distance from roads was at least $500 \mathrm{~m}$, the fire danger associated with the proximity to roads was set to 0 . Catry et al. (2009) reported a strong association between ignition risk and distance from roads for distances of $0-500 \mathrm{~m}$. The initial distances were also rescaled to values of between 0 and 1 , with 1 indicating immediate proximity to a road or settlement and 0 corresponding to a distance of $500 \mathrm{~m}$ or more
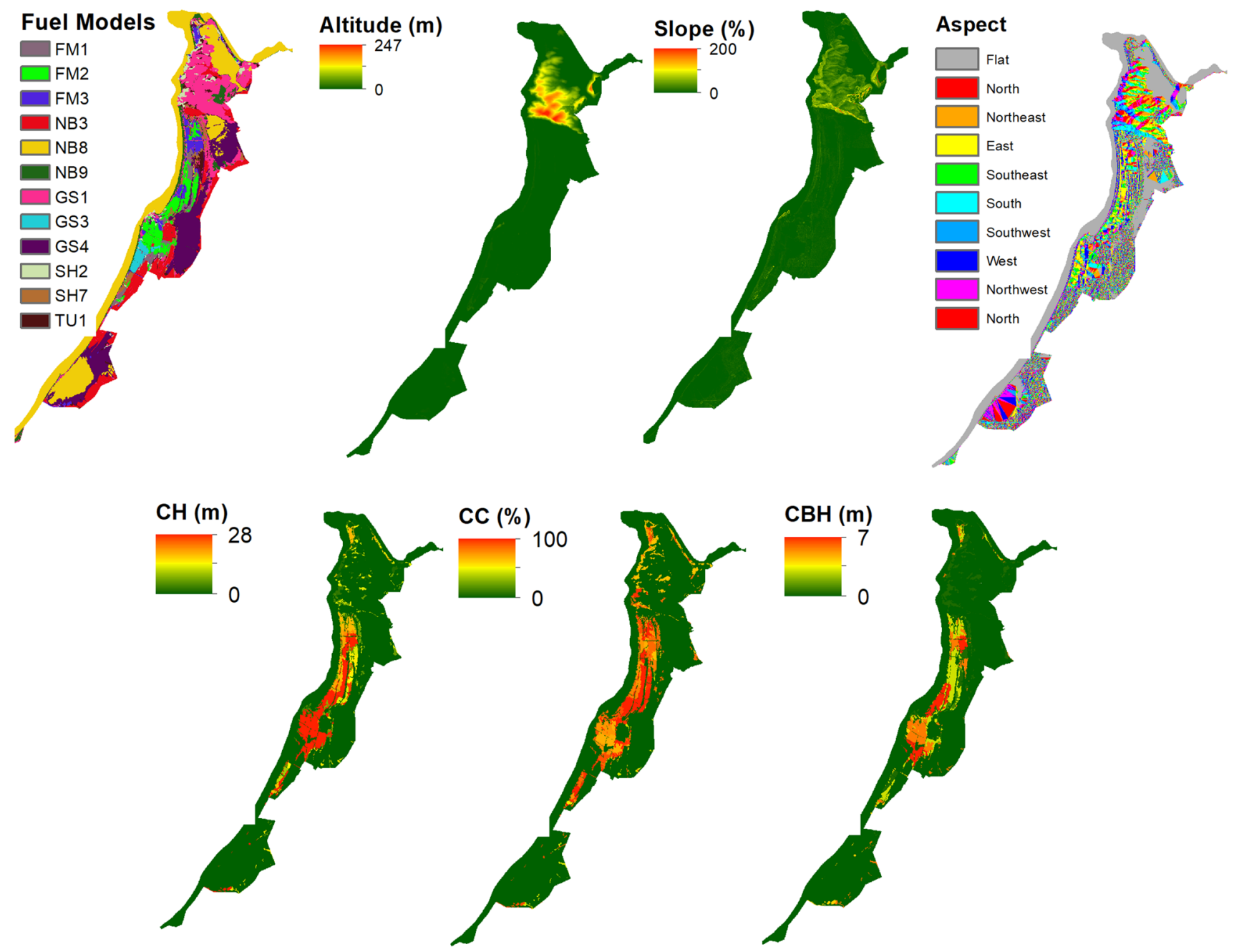

Fig. 2 Raster maps used as input data in the fire simulation with FlamMap 
from roads. This process generated the human index (HI) for integration into the FDI.

Finally, the pyric history was also taken into account when estimating the final FDI. Data from all fires that have been recorded in the area over the last 40 years were collected from the local forest service and were vectorized into polygons and points. The kernel density estimation function tool in ArcGIS 10 was employed to convert the point data into an estimation of the fire risk based on the pyric history of the area. The values were also rescaled to lie between 0 and 1 , with 0 indicating a low risk and 1 the highest risk, in order to generate the fourth component of the FDIthe pyric history index $(\mathrm{PH})$. The inclusion of an index to depict the spatial pattern of past fire ignitions is of particular importance in studies that attempt to estimate fire risk. In Greece, and possibly elsewhere in the Mediterranean where free-range livestock breeding is still practiced, fires are often deliberately set in areas that have relatively low flammability but have high potential for use as rangelands in order to improve grazing conditions. Although these ignitions rarely result in large and intensive fires, their inclusion in the FDI is expected to increase the estimated fire danger in areas with low flammability but a high frequency of past ignitions. This should result in more effective protection of these areas and should help to prevent deliberate ignitions in the future.

Fire danger is a function of three main factors: the probability of a fire, the behavior of a fire, and the damage that it causes to ecosystems, properties, and infrastructure (Calkin et al. 2010; Finney 2005). Fire occurrence is reportedly positively associated with proximity to anthropogenic infrastructure, including roads and settlements (Clarke et al. 2019). Similarly, pyric history is a proxy for the ignition pattern in an area. It was therefore decided that these two factors that are both proxies for ignition risk should have a combined weight of $30 \%$, with $20 \%$ assigned to the proximity to anthropogenic infrastructure and $10 \%$ to the spatial pattern of past ignitions. Fire intensity and rate of spread are both important components of fire behavior and largely determine how catastrophic a fire can be. They are both related to the fuel type and condition, and it is essential to quantify them and integrate them into the fire danger estimation (Scott et al. 2013). These two fire behavior characteristics constitute the main components of the FDI, so their weights were set at $50 \%$ and $20 \%$, respectively, based on the reported literature. The above four components were integrated into the final FDI using the following formula:

$\mathrm{FDI}=0.5 \times \mathrm{FI}+0.2 \times \mathrm{ROS}+0.2 \times \mathrm{HI}+0.1 \times \mathrm{PH}$.

Figure 3 shows a flow chart for the entire study.

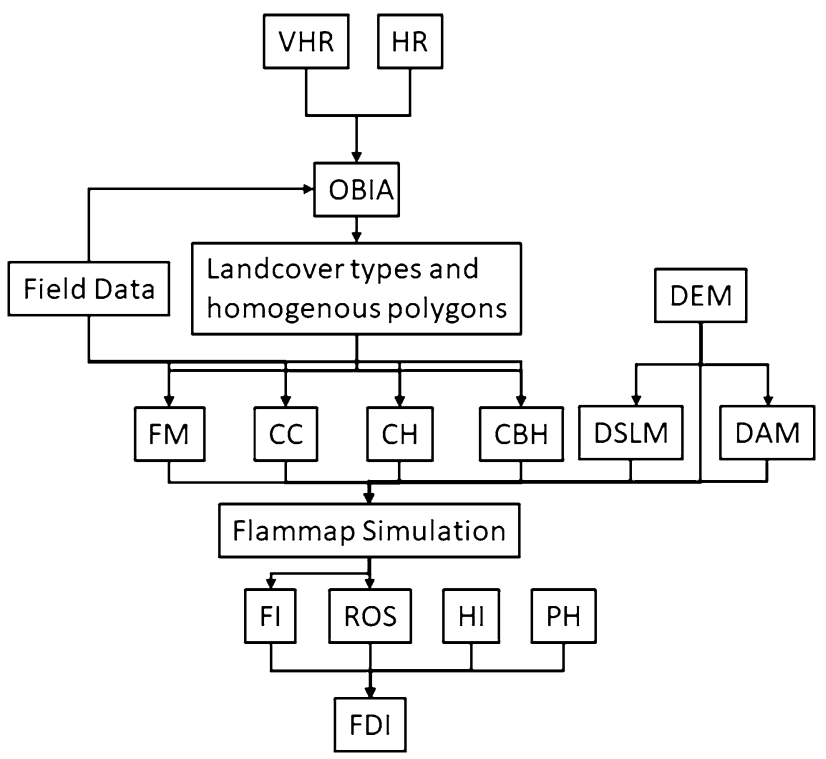

Fig. 3 Flow chart for calculating the FDI

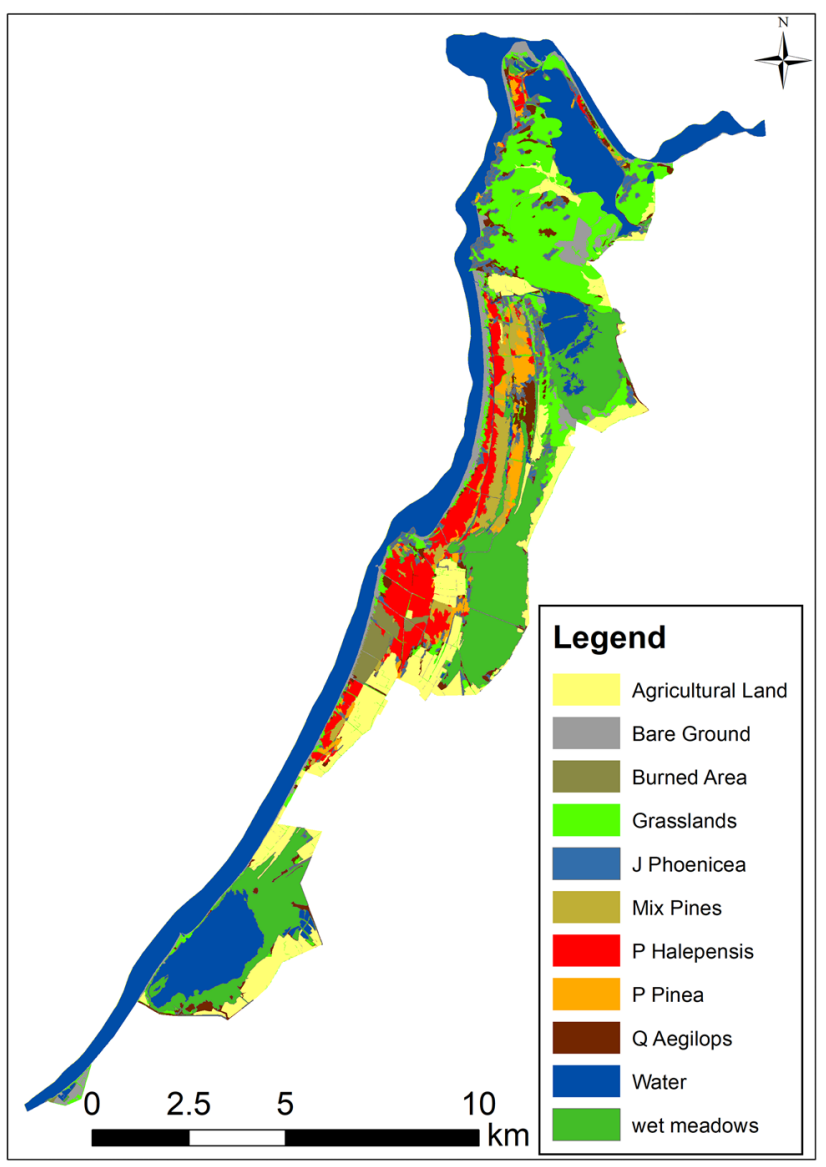

Fig. 4 Land cover map of the study area 


\section{Results}

The overall accuracy of the mapping product resulting from OBIA (Fig. 4) was estimated at $89 \%$, while the kappa statistic was 0.88 , indicating excellent performance by the classifier. Thus, the map was sufficiently accurate to be utilized for further analysis in the current study. The detailed accuracy statistics are presented in Table 4 in the Appendix. As expected, wet meadows and water, including sea water, were the dominant land cover types in the study area (percentage cover: 31.2 and $18.2 \%$, respectively; Table 2). Grasslands

Table 2 Land cover class distribution in the study area

\begin{tabular}{lcl}
\hline Land cover class & Area (ha) & Cover (\%) \\
\hline Agricultural land & 972.7 & 11.1 \\
Bare ground & 375.0 & 4.3 \\
Burned area & 127.9 & 1.5 \\
Grasslands & 1349.2 & 15.4 \\
J. phoenicea & 344.0 & 3.9 \\
Mixed pines & 252.1 & 2.9 \\
P. halepensis & 589.9 & 6.7 \\
P. pinea & 202.9 & 2.3 \\
Q. aegilops & 237.4 & 2.7 \\
Water & 2738.4 & 31.2 \\
Wet meadows & 1594.5 & 18.2 \\
Total & 8784.01 & 100 \\
\hline
\end{tabular}

also covered a significant proportion of the study area, especially in the northern part, which was the most degraded part of the study area due to heavy grazing by domestic animals. The three formations of pine, which are often associated with high-intensity crown wildfires, collectively covered almost $12 \%$ of the study area.

The process of assigning fuel models to the various land cover types revealed that the great majority (84\%) of pine forests were eventually assigned the fuel model FM01, which is characterized by the highest fuel load among the three available fuel models. This is due to the existence of a dense shrub understorey in the majority of the pine formations, which makes the stands extremely fire prone. J. phoenicea formations were assigned in almost equal proportions to the two available fuel models for shrubland formations, indicating the existence of both moderate- and high-density formations in the study area.

The fire simulation performed using FlamMap provided two of the four components of the FDI developed in the current study, and these two components are also the most important since they have a collective weight of 0.7 in the relevant formula. Fireline intensity varied a lot between the various land cover classes as a result of differences in vegetation structure and composition. The highest values were, as expected, observed in pine forests, while the lowest were seen in grasslands, followed by the recently burned sites (Fig. 5). No significant differences were noted between the three pine formations, which was rather surprising given the differences in understorey vegetation and $\mathrm{CC}$ between them.
Fig. 5 Estimated fireline intensity for the burnable land cover classes in the study area. Different letters indicate statistically significant differences. The vertical bars denote $95 \%$ confidence intervals

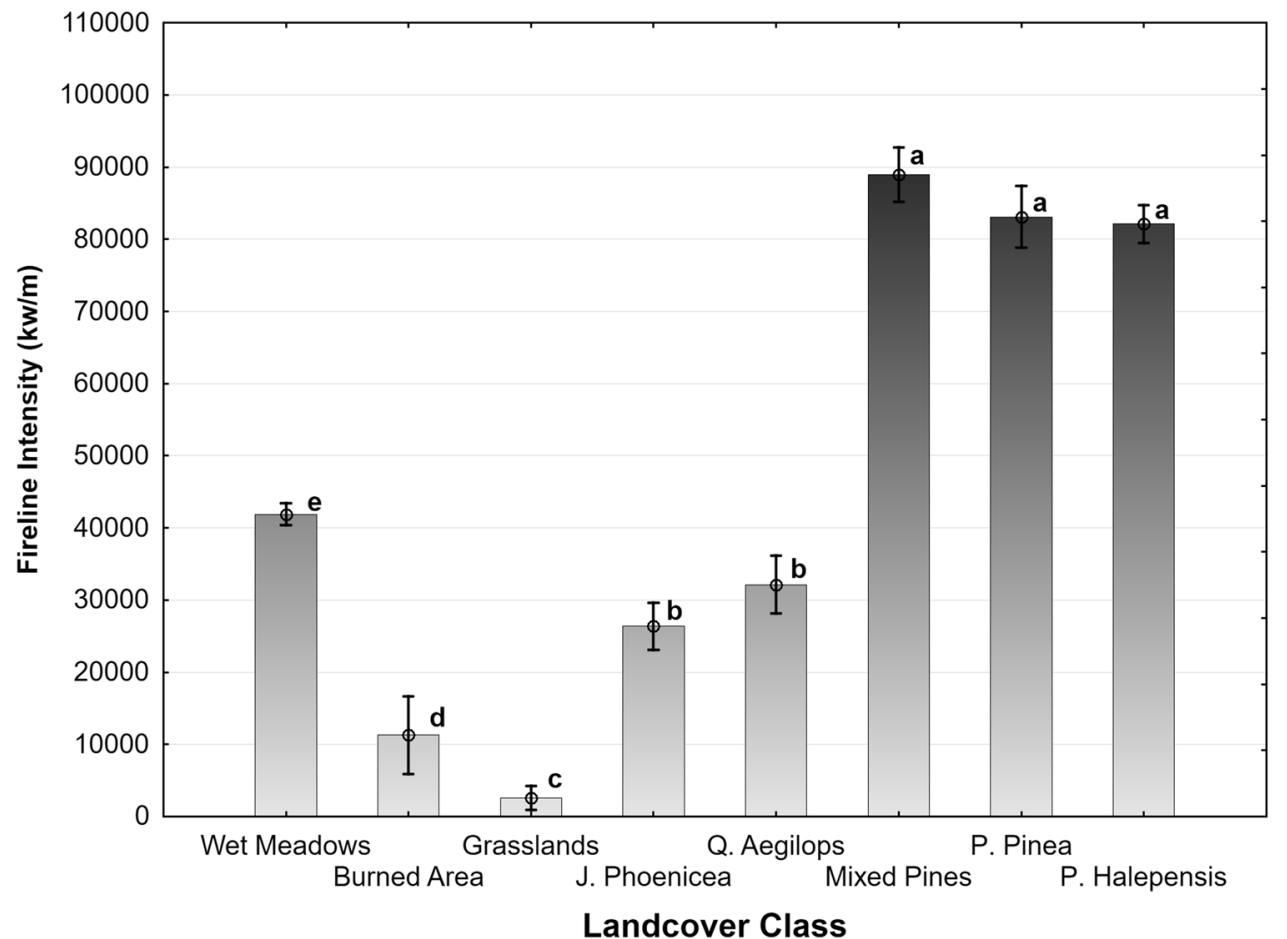


Fig. 6 Estimated rate of spread for the burnable land cover classes in the study area. Different letters indicate statistically significant differences. Vertical bars denote $95 \%$ confidence intervals

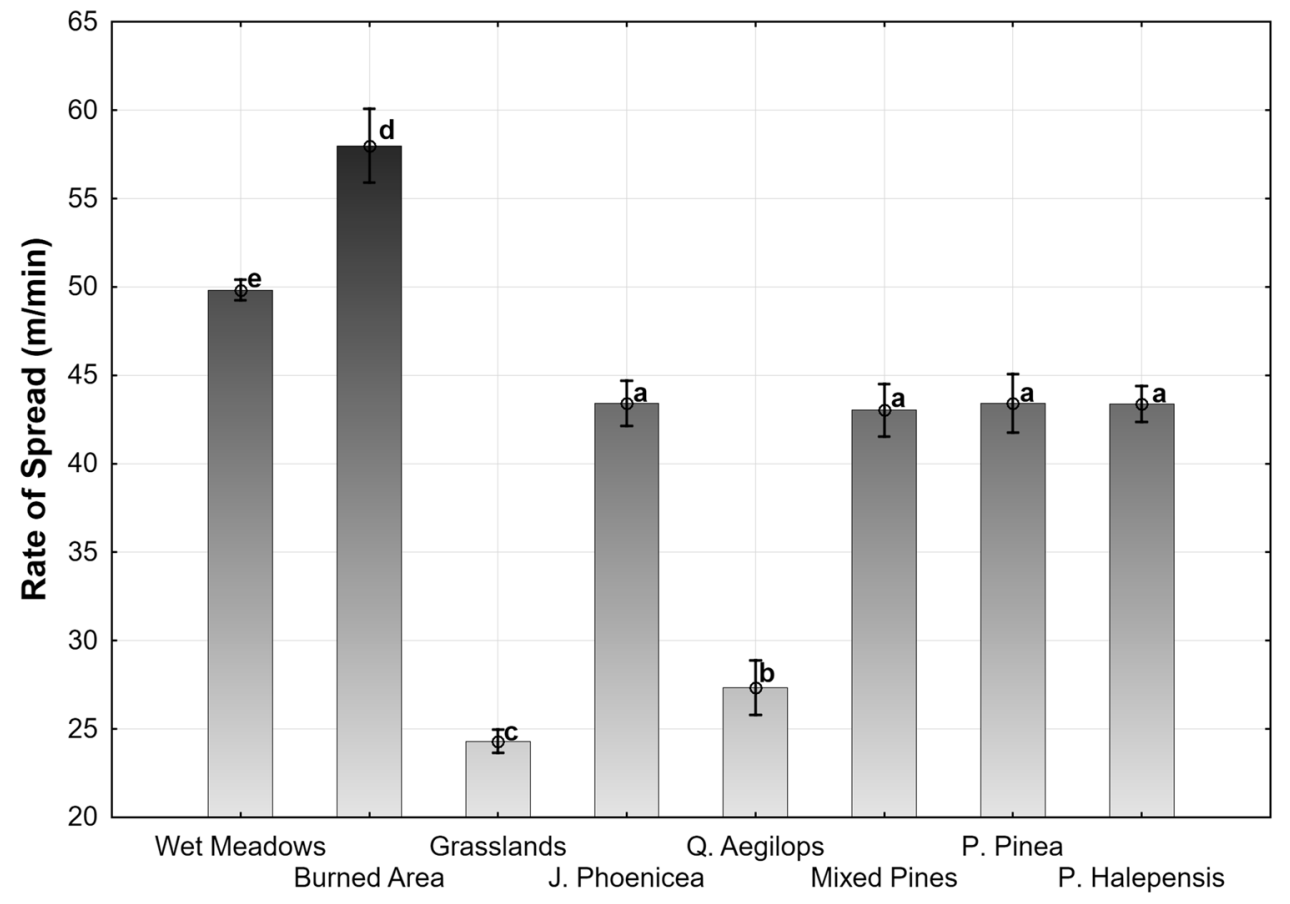

Landcover Class
This probably indicates that even a small cover of understorey vegetation is enough to initiate a crown fire, which generally leads to wildfires of high intensity.

Rate of spread also varied significantly between the various land cover types (Fig. 6). The highest values were observed in recently burned areas and wet meadows, where rate of spread reached or exceeded $50 \mathrm{~m} / \mathrm{min}$, while the lowest were seen in $Q$. aegilops formations and grasslands. The slow advancement of fire on grasslands was not expected given that these formations consist of fine and easily burnable fuel. However, the grasslands in the study area are degraded due to heavy grazing and frequent fires. This results in a very low and often discontinuous fuel load that prevents the rapid spread of fire. Wet meadows, on the other hand, have high fuel loads due to their favorable soil moisture conditions. When they dry during the summer period, they constitute an extremely flammable fuel, which explains the high rates of spread observed for wet meadows in the current study. No significant differences were observed between the three pine formations and the J. phoenicea shrublands, which exhibited moderate to high rates of
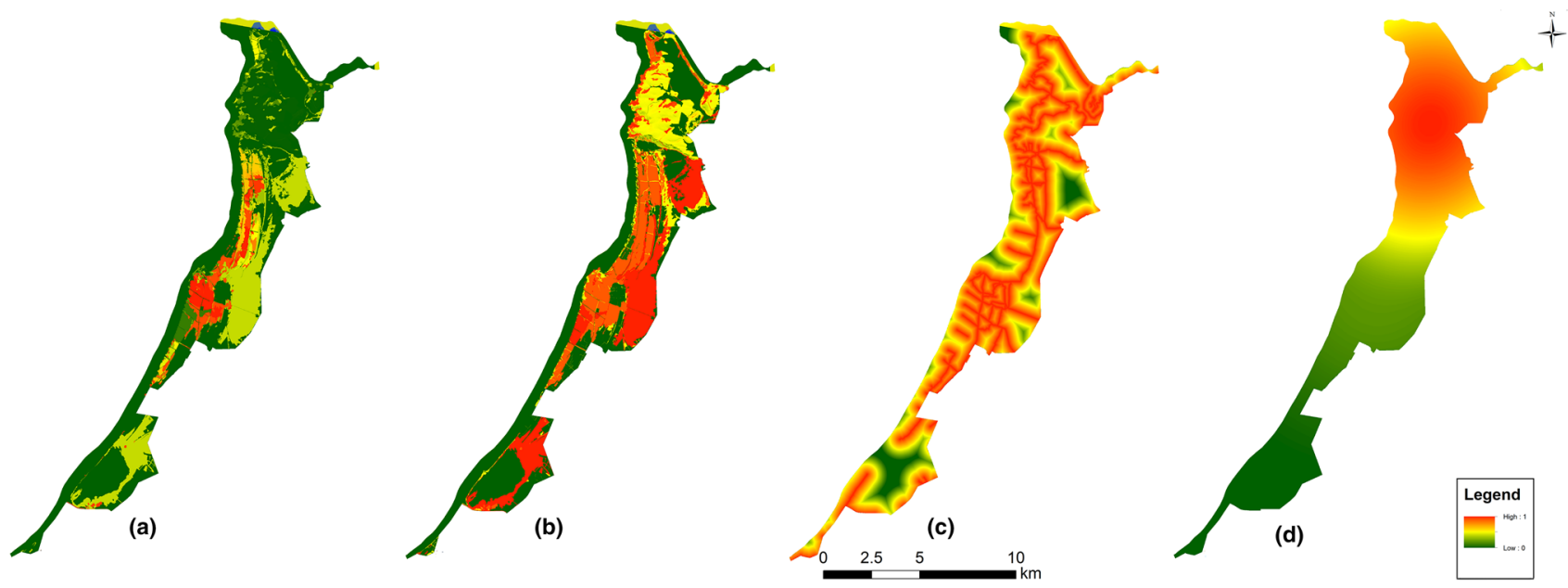

Fig. 7 Rescaled values of the four components of the FDI: fireline intensity (a), rate of spread (b) human impact (c), and pyric history (d) 


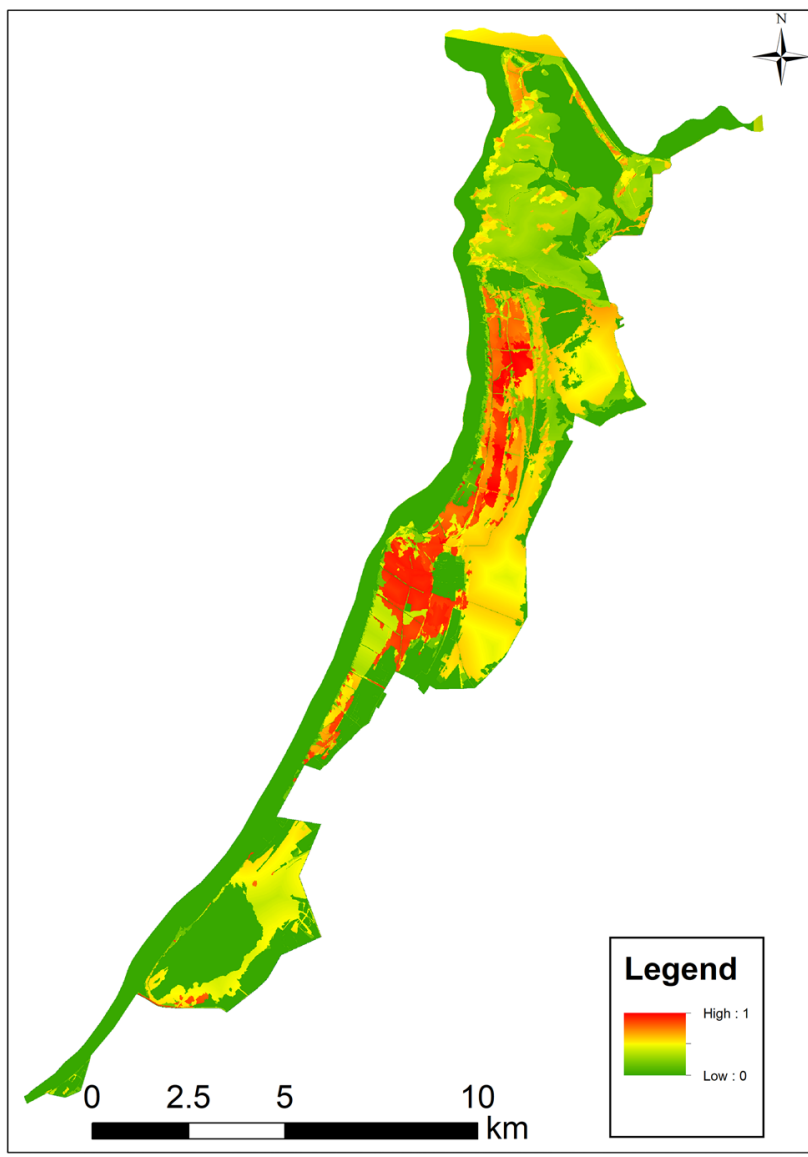

Fig. 8 Map of the FDI calculated for the study area spread. The rescaled values of fireline intensity and rate of spread (Fig. 7a, b) were integrated into the FDI.

Values for the anthropogenic activity, estimated as the distance to roads and settlements (Fig. 7c), indicate that almost the entire area is highly vulnerable to accidental wildfires that are often associated with high anthropogenic activity. Although the dense network of roads and fuel breaks (which are also used as roads) may aid fire suppression efforts, it may also increase the fire risk in areas with high human presence, such as the area studied here.

The analysis of the pyric history of the area (Fig. 7d) provides a clear indication of the origin of a large proportion of the wildfire incidents in the study area, as well as in Greece in general. Fires seem to occur more frequently in the northern and hilly parts of the study area, which are covered primarily with grasslands and only sparsely with $J$. phoenice a and $Q$. aegilops. Based on the fire simulation results presented above, these are the least fire-prone parts of the study area. The frequent occurrence of fire there can only be explained by the deliberate initiation of fires by shepherds to improve grazing conditions and prevent shrub encroachment into the rangelands (this is a common practice among shepherds).

The integration of the four components into the FDI using the formula above resulted in FDI values of between zero in the nonburnable land cover classes and almost 1 in the areas that scored the highest (Fig. 8). Analysis of the results for the land cover classes revealed that the greatest danger from fire is associated with the pine formations in the area, especially the pure and mixed $P$. pinea stands (the average
Fig. 9 Estimated FDIs for the burnable land cover classes in the study area. Different letters indicate statistically significant differences. Vertical bars denote 95\% confidence intervals

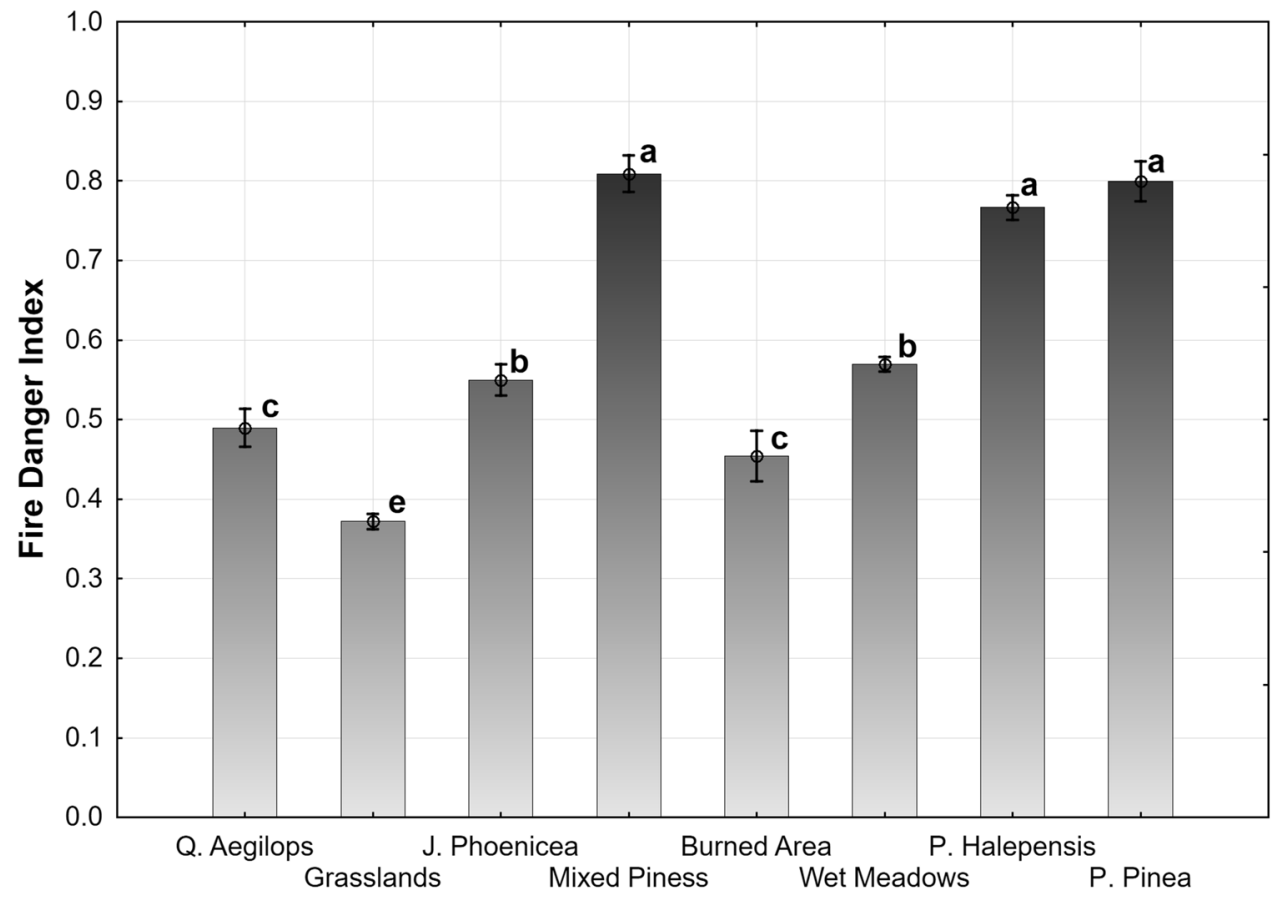

Landcover Class 
value of the FDI in these stands is 0.8). Exhibiting a slightly, but not significantly, lower fire risk are the P. halepensis forests (Fig. 9). The least fire-prone vegetation formation is the grasslands, followed by $Q$. aegilops and recently burned areas, with an average FDI of $<0.5$. The FDIs calculated for J. phoenicea shrublands and wet meadows are slightly above 0.5 .

\section{Discussion and conclusion}

The current study integrates remote-sensing data and methods with fire simulation techniques to generate a FDI that is expected to assist in detecting areas at a critical state in terms of fire potential. Furthermore, the integration of the FDI into an automatic fire detection and decision support system is expected to improve its detection accuracy and aid decision making regarding the mobilization of fire suppression resources and the adoption of appropriate tactics. The methods employed are well documented in the literature, and the procedure adopted is straightforward, meaning that it is transferable to other fire-prone areas. The data employed are inexpensive or free to obtain, while the continuously improving availability and quality of remote-sensing data ensure that this approach will remain applicable in the future. Remote-sensing data and methods are widely used to facilitate the effective management of wildfires in an effective manner by providing mapping products with high spatial accuracy and predictive value for potential fire behavior and risk (Keramitsoglou et al. 2008; Pan et al. 2016; Sanchez et al. 2018).

The results presented here indicate that a large proportion of the Kotychi and Strofylia Wetlands National Park is in critical danger of a high-intensity wildfire. The stone pine forests, which are among the most valuable ecosystems in the area and are of high conservational importance for Europe, are those that face the greatest danger. Given the geographic isolation of the area and the small dispersal ability of the species that inhabit it, a wildfire could have a significant ecological cost, threatening the existence of the species in the area. The presence of a dense understorey appears to be the main factor that could turn a surface fire into a crown fire; such a fire has a very high heat yield and is difficult to restrict and suppress. Fuel reduction practices have been suggested in the literature as an appropriate way to compensate for the significantly increased fuel loads observed in recent decades (Kalabokidis and Omi 1998). The removal of the shrub understorey of pine forests in zones next to roads or at the wildland-urban interface may form part of the strategy for reducing the risk of fire.

It is now widely accepted that wildfires require the integration of several disciplines such as forest and landscape ecology, fire ecology, pyrology, environmental modeling, remote sensing, and others in a supplementary manner for effective management. Furthermore, particular attention needs to be paid to the pyric history of the region of interest, local knowledge, historical land uses, and current trends in order to unravel the mysteries of wildfire and increase the effectiveness of fire prevention and fire suppression. The aim of an effective wildfire management strategy should not be to completely eliminate wildfires, which is practically impossible, but to restrict their ecological, economic, and social cost.

Acknowledgements The study was conducted within the project "Forest Monitoring System for Early Fire Detection and Assessment in the Balkan-Med Area (SFEDA)" (MIS: 5013503).

Funding The study was cofunded by the European Union within the framework of the program "Interreg V-B Balkan-Mediterranean 20142020 " and by national funds.

\section{Compliance with ethical standards}

Conflict of interest The authors declare that they have no conflict of interest.

Open Access This article is licensed under a Creative Commons Attribution 4.0 International License, which permits use, sharing, adaptation, distribution and reproduction in any medium or format, as long as you give appropriate credit to the original author(s) and the source, provide a link to the Creative Commons licence, and indicate if changes were made. The images or other third party material in this article are included in the article's Creative Commons licence, unless indicated otherwise in a credit line to the material. If material is not included in the article's Creative Commons licence and your intended use is not permitted by statutory regulation or exceeds the permitted use, you will need to obtain permission directly from the copyright holder. To view a copy of this licence, visit http://creativecommons.org/licenses/by/4.0/.

\section{Appendix}

See Tables 3 and 4 . 


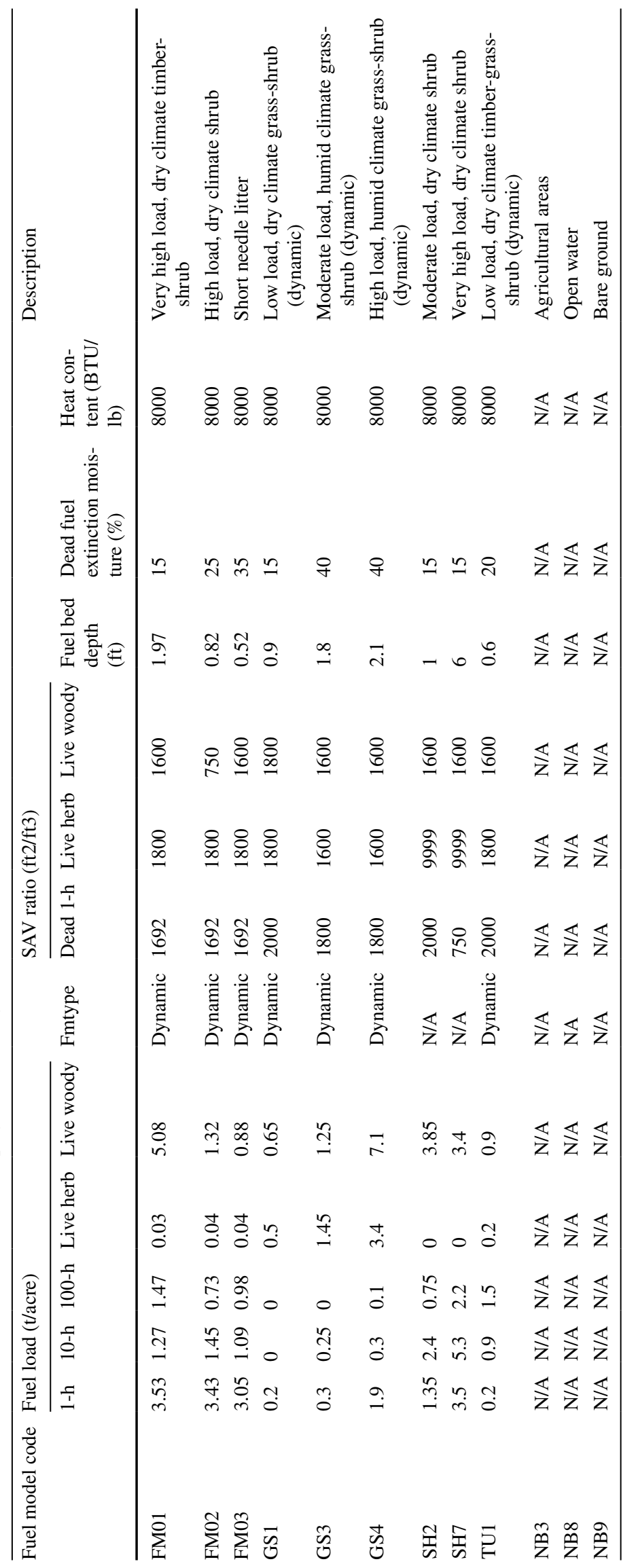




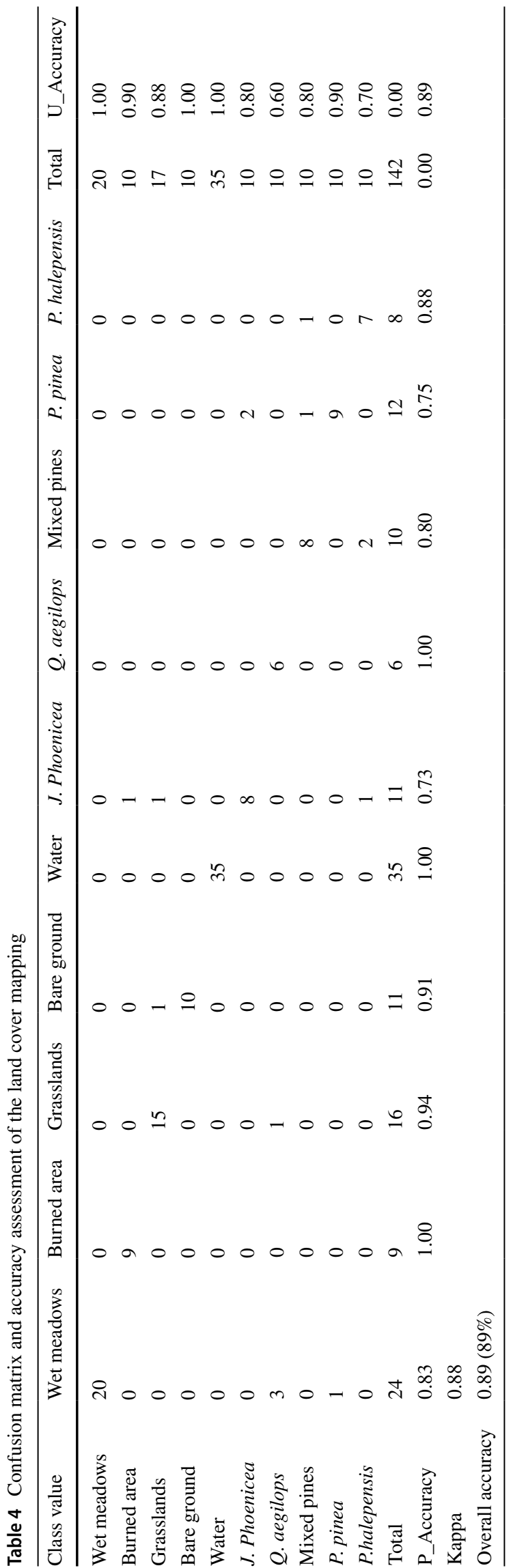

\section{References}

Ager AA, Preisler HK, Arca B, Spano D, Salis M (2014) Wildfire risk estimation in the Mediterranean area. Environmetrics 25:384-396

Anderson HE (1982) Aids to determining fuel models for estimating fire bahavior. USDA Forest Service General Technical Report INT-122. USDA Forest Service, Ogden

Bock M, Xofis P, Mitchley J, Rossner G, Wissen M (2005) Objectoriented methods for habitat mapping at multiple scales-case studies from Northern Germany and Wye Downs, UK. J Nat Conserv 13:75-89

Calkin DE, Ager AA, Gilbertson-Day J (2010). Wildfire risk and hazard: procedures for the first approximation. Gen. Tech. Rep. RMRS-GTR-235. Rocky Mountain Research Station, Fort Collins, $\mathrm{p} 62$

Catry FX, Rego FC, Bacao F, Moreira F (2009) Modeling and mapping wildfire ignition risk in Portugal. Int J Wildland Fire 18:921-931

Clarke H, Gibson R, Cirulis B, Bradstock RA, Penman TD (2019) Developing and testing models of the drivers of anthropogenic and lightning-caused wildfire ignitions in south-eastern Australia. J Environ Manag 235:34-41

Dimitrakopoulos AP (2002) Mediterranean fuels models and potential fire behavior in Greece. Int J Wildland Fire 11:127-130

Dimitrakopoulos AP, Vlahou M, Anagnostopoulou ChG, Mitsopoulos ID (2011) Impact of drought on wildland fires in Greece: implications of climate change? Clim Change 109:331-347

Drusch M, Bello D, Carlier S, Colin O, Fernandez V, Gascon F, Hoersch B, Isola C, Laberinti P, Martimort P, Meygret A, Spoto F, Sy O, Marchese F, Bargellini P (2012) Sentinel-2: ESA's optical high-resolution mission for GMES operational services. Remote Sens Environ 120:25-36

Finney MA (2005) The challenge of quantitative risk analysis for wildland fire. Forest Ecol Manag 211:97-108

Finney MA (2006) An overview of FlamMap fire modeling capabilities. USDA Forest Service Proceedings RMRS-P-41. Rocky Mountain Research Station, Fort Collins

Kalabokidis KD, Omi PN (1998) Reduction of fire hazard through thinning/residue disposal in the urban interface. Int J Wildland Fire 8:29-35

Kalabokidis K, Palaiologou P, Gerasopoulos E, Giannakopoulos C, Kostopoulou E, Zerefos C (2015) Effect of climate change projections on forest fire behavior and values-at-risk in southwestern Greece. Forests 6:2214-2240

Keramitsoglou I, Kontoes C, Sykioti O, Sifakis N, Xofis P (2008) Reliable, accurate and timely forest mapping for wildfire management using ASTER and Hyperion satellite imagery. Forest Ecol Manag 255:3556-3562

Koutsias N, Xanthopoulos G, Founda D, Xystrakis F, Nioti F, Pleniou M, Mallinis G, Arianoutsou M (2013) On the relationships between forest fires and weather conditions in Greece from longterm national observations (1894-2010). Int J Wildland Fire 22:493-507

Mitsopoulos I, Mallinis G, Arianoutsou M (2015) Wildfire risk assessment in a typical Mediterranean wildland-urban interface of Greece. Environ Manag 55:900-915

Molina JR, Martin T, Silva FRY, Herrera MA (2017) The ignition index based on flammability of vegetation improves planning in the wildland-urban interface: a case study in Southern Spain. Landsc Urban Plann 158:129-138

Naveh Z (1990) Fire in the Mediterranean-a landscape ecological perspective. In: Goldammer JG, Jenkins MJ (eds) Fire in ecosystems dynamics. SPB Academic, The Hague, pp 1-20

Nunes L, Lopes D, Castro Rego F, Gower S (2013) Aboveground biomass and net primary production of pine, oak and mixed 
pine-oak forests on the Vila Real district, Portugal. For Ecol Manag 305:38-47

Palaiologou P (2015) Design of fire behaviour prediction and assessment with the use of geoinformation. PhD dissertation. University of the Aegean, Lesbos (in Greek).

Pan J, Wang W, Li J (2016) Building probabilistic models of fire occurrence and fire risk zoning using logistic regression in Shanxi Province, China. Nat Hazards 81:1879-1899

Pausas JG, Fernandez-Munoz S (2012) Fire regime changes in the Western Mediterranean Basin: from fuel-limited to draught-driven fire regime. Clim Change 110:215-226

Ruiz-Peinado R, del Rio M, Montero G (2011) New models for estimating the carbon sink capacity of Spanish softwood species. For Syst 20:176-188

Sanchez SY, Martinez-Grana A, Frances FS, Picado MM (2018) Mapping wildfire ignition probability using Sentinel 2 and LiDAR (Jerte Valley, Cáceres, Spain). Sensors 18:826. https://doi. org/10.3390/s18030826

Scott JH, Burgan RE (2005) Standard fire behaviour fuel models: a comprehensive set for use with Rothermel's surface fire spread model. In: Gen. Tech. Rep. RMRS-GTR-153. Rocky Mountain Research Station, Fort Collins, p 72

Scott JH, Thompson MP, Calkin DE (2013) A wildfire risk assessment framework for land and resource management. In: Gen. Tech. Rep. RMRS-GTR-315. Rocky Mountain Research Station, Fort Collins, $\mathrm{p} 83$

Smiris P, Maris F, Vitoris K, Stamou N, Kalambokidis K (2000) Aboveground biomass of Pinus halepensis Mill. forests in the Kassandra Peninsula-Chalkidiki. Silva Gandavensis 65:173-187

Trimble Inc. (2014) eCognition developer reference book. Trimble Inc., Munich
Tsiourlis GM (1992) Etude d'un écosystème de maquis à Juniperus phoenicea L. (Naxos, Cyclades, Grèce): phytomasse et nécromasse épigées. B Ecol (Ecologie) 23:59-69

Tsiourlis GM (1994) Phytomasse et productivité primaire d'une phytocénose peupleraie (Populus cultivar Robusta) d'âges différents (Hainaut, Belgique). Belg J Bot 127:134-144

Tsiourlis GM (1998) Evolution of biomass and productivity of kermes oak grazed and ungrazed shrubs in an insular phryganic ecosystem in Naxos, Greece. In: Papanastasis VP, Peter D (eds) Proceedings of the International Workshop on Ecological Basis of Livestock Grazing in Mediterranean Ecosystems, Thessaloniki, Greece, 1997. EC Printing Office, Luxembourg, pp 86-89

Tsiourlis GM, Kasapidis P (1999) Contribution to the study of degradation-desertification processes in central Crete: structure, dynamics and function of Mediterranean ecosystems in relation to overgrazing in Asterousia and Psiloritis mountains (Greece). Contribution of the Crete team to the DeMon 2 project [Environment and Climate Contract ENV4-CT95-0166 (DG 12-DTEE)]. University of Crete/National Agricultural Research Foundation, Heraklion/ Thessaloniki, p 58.

Tsiourlis GM, Konstantinidis P, Sklavou P (2003) Biomass of Quercus coccifera Mediterranean shrublands of Lagadas County, Greece. GeoRange project [DGXII, EESD, EVK2-CT2000-0009]. NAGREF Forest Research Institute, Athens, p 20

Turco M, Bedia J, Di Liberto F, Fiorucci P, von Hardenberg J, Koutsias $\mathrm{N}$ et al (2016) Decreasing fires in Mediterranean Europe. PLoS ONE 11(3):e0150663. https://doi.org/10.1371/journal.pone.01506 63

Xofis P, Poirazidis K (2018) Combining different spatio-temporal resolution images to depict landscape dynamics and guide wildlife management. Biol Conserv 218:10-17 